\title{
Effects of Student Feedback on Teaching Competence of Student Teachers: A Microteching Experiment
}

\author{
Vibha Chawla \\ Rayat-Bahra College of Education, India \\ Praveen Thukral \\ Mohan Lal Institute of Education, India
}

\begin{abstract}
This study is an attempt to evaluate the effects of student feedback in developing teaching competence among student teachers. The study was conducted on ten student-teachers of one of the reputed colleges of Panjab University using single-group pretest-posttest design. The efficiency of employing all the selected skills has been calculated by using observation schedule cum rating scale for each skill. The efficiency has been found to be greater than $83 \%$ in case of all the student-teachers trained through student feedback. The coefficient of correlation between Efficiency of Using Five Selected Teaching Skills and Posttest Baroda General Teaching Competence Scale Score has been found to be 0.260 . Also, $10 \%$ of the student-teachers move from average to high performance category on Stanine scale. In brief, student feedback has been found to be effective in improving the general teaching competence of student-teachers.
\end{abstract}

Keywords: Student feedback; Teaching competence; Teaching skills; Microteaching

\section{Introduction}

Teacher education programmes play a vital role in the total education system. The quality of training the trainees get is reflected in their competence later. It is necessary to provide good training at the teacher training institutions, as the teacher is nation builder. The aim of teacher education is to shape and strengthen the basic teaching techniques and provide feedback. Feedback is the most important component as it contributes significantly to behaviour modification of the student teachers.

The student teaching focuses on objectives, accountability and as such implies specific criteria of careful evaluation, which is based on feedback. Teacher Education should provide competence and focus on student teachers acquisition of specific teaching skills. The principle of feedback is quite useful in developing teaching skills among student teachers and making them competent teacher by increasing their teaching competence.

Pupils are real critics of their teachers. They can critically differentiate between the desirable and undesirable behaviours of their teachers in the classroom situation. It is also necessary from the psychological point of view, since the teachers are trained to teach students. Thus feedback from students can bring improvement in competence level of teachers. 
Feedback in teacher education is defective. It is general and lacks pinpointed-ness (Passi (1976), Passi and Lalitha (1976) and Das et al. (1980)). Purohit (1987) found that microteaching feedback helps significantly in the classroom performance of language teachers. Microteaching feedback appeared to invite more pupil response than interaction analysis feedback. Walker (1991) used Classroom assessment techniques in a large survey college course in psychology to monitor student performance and collect other forms of student feedback. As a result, student-teacher role relations changed, the teacher adopted the role of learning coach and reduced lecture content, and the classroom environment was enlivened. Ellis (1993) suggested ways to improve instructional quality which include identification of teaching skills through consultation with expert teachers, specification of teaching standards, use of student feedback on teaching, awarding of distinguished teaching awards, assessment of teaching competence upon hiring, a faculty development course, and encouragement of self/peer evaluation.

Rauch and Fillenworth (1995) noted that motivating students to apply new study strategies could be difficult but that obtaining student feedback gives teachers insight into the matter. Johnson (2000) outlined the difficulties of conducting action research and recommended student perceptual surveys to teachers who want to do action research. He pointed out the importance of students' perceptions of the learning environment and student feedback for professional development. Bridges et al., (2002) concluded that the assessment of students helps the teacher to evaluate the students' performance and the effectiveness of the teacher's effort.

Joshi (2002) proposed that there are two dimensions of student feedback. One is quantitative dimension that can be ascertained through various types of questionnaires filled by students; second one is qualitative dimension that is ascertained through the interaction with the students. Considering the both there have been useful tips for improvement in teachers behaviour. Hendry et al. (2007) explored the relationship between teachers' approaches to teaching and responses to qualitative student feedback in a problem-based medical program. Results were that most teachers report making changes to their teaching in response to students' suggestions at least sometimes.

In most of the studies the researchers found that the feedback provided by the students to their teachers will add positively to their classroom effectiveness. But the areas like whether efficiency of using particular teaching skills developed have any bearing on general teaching competence, how level of performance of teachers changes, whether theoretical knowledge possessed by teachers is having any relationship with general teaching competence developed by using student feedback needs to be explored. The present study is an attempt to evaluate the effect of Student Feedback in developing teaching skills and thereby teaching competence among student teachers. Specific objectives of the study were:

1. To find out the effect of efficiency of using the different skills acquired through Student Feedback on General Teaching Competence of student teachers.

2. To determine the effect of Student Feedback on the Level of Performance of student teachers.

3. To ascertain the effect of Student Feedback on the General Teaching Competence of student teachers.

4. To assess the relationship between cognitive-based-competence and performancebased-competence of student teachers trained through Student Feedback. 


\section{Methodology}

\section{Sample}

The sample of 10 student teachers was selected randomly from student teachers admitted in 2005-06 session in D.A.V. College of Education, Hoshiarpur and it was consisted of six female and four male student teachers. The four extraneous variables which may affect the dependent variables of study i.e. the Marks of B. Ed. Entrance Test (MBEET) [Maximum marks for the Test was 350], Marks of Teaching Learning Process Paper (MTLPP) [Maximum marks for the paper was 80], Percentage of Marks in Graduation (PMG) and Index of Academic Motivation (IAM) on the basis of JIM Scale were noted/ measured. The mean and standard deviation (SD) of these extraneous variables for the sample chosen were:

\begin{tabular}{|c|c|c|c|c|}
\hline Extraneous Variable & MBEET & MTLPP & PMG & IAM \\
\hline Mean & 122.30 & 34.70 & 60.96 & 105.70 \\
\hline SD & 11.01 & 12.42 & 8.36 & 13.42 \\
\hline
\end{tabular}

\section{Design of the Study}

The study was done by using Single-group Pretest-Posttest design. In this the investigator measured the dependent variable (teaching competence), before the independent variable (Student Feedback) is applied and then he takes the measurement of dependent variable again. The five teaching skills such as Skill of Introducing the Lesson (ITL), Skill of Explanation $(E)$, Skill of Probing Questions (PQ), Skill of Stimulus Variation (SV), and Skill of Blackboard Writing (BW) were developed among the student teachers with the help of Student Feedback. The microteaching cycle adopted for the present study consists of following microteaching sessions:

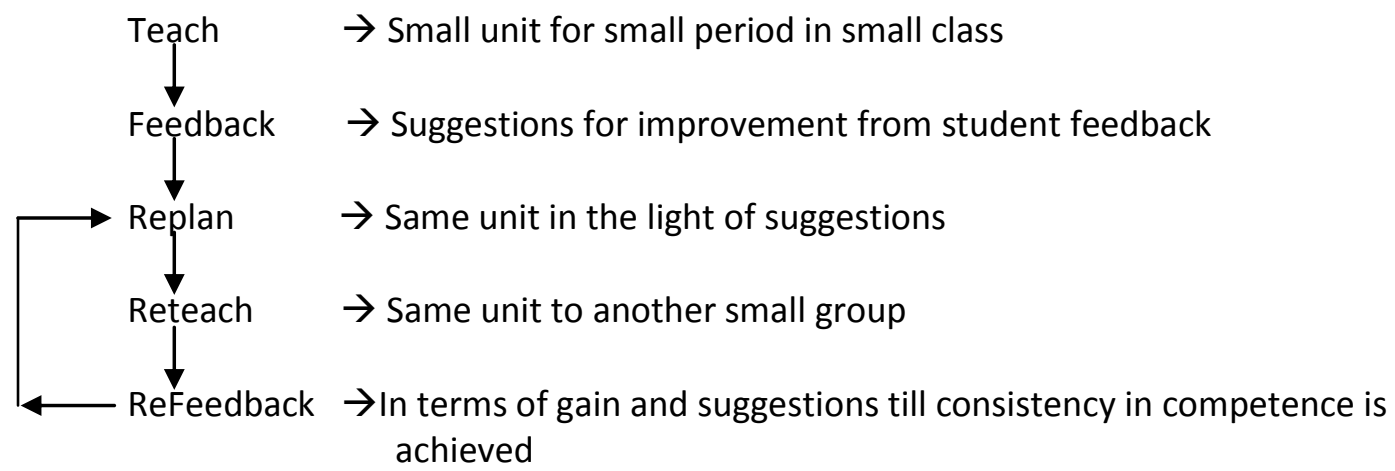

The time duration allowed for each microteaching session except replan session was 6 minutes. The time duration allowed for replan session was 12 minutes. Thus total duration for a microteaching cycle was 36 minutes.

\section{Tools Used}

The following tools were used in this study: 
1. Baroda General Teaching Competence Scale, prepared at the Centre of Advanced Study in Education, (CASE) M.S. University, Baroda

2. Observation Schedule cum Rating Scale for the Skill of Introducing the Lesson

3. Observation Schedule cum Rating Scale for the Skill of Explanation

4. Observation Schedule cum Rating Scale for the Skill of Probing Questioning

5. Observation Schedule cum Rating Scale for the Skill of Stimulus Variation

6. Observation Schedule cum Rating Scale for the Skill of Black Board Writing

7. Questionnaire for Student Teachers to evaluate their cognitive aspect

Baroda General Teaching Competence Scale: Baroda General Teaching Competence Scale is based on the lists of teaching skills developed at the Centre of Advanced Study in Education at the M. S. University of Baroda, Baroda. The Baroda General Teaching Competence Scale (BGTC Scale) covers the five major aspects related to teaching competence which are as follows: (A) Planning; (B) Presentation; (C) Closing; (D) Evaluation; (E) Managerial. The BGTC is a seven point scale from 'not at all' to 'very much'. Score zero represents 'not at all' and score 6 represents 'very much'. All the twenty-one items on the scale are positive and maximum total score is 126 . The inter-observer reliability coefficient ranged from 0.85 to 0.91 for the sample for which original scale was developed.

Observation Schedule cum Rating Scale for the Skill of Introducing The Lesson: It has got five components namely: Using previous experience of pupils, Proper use of device/technique, Overall impression, Relevance, Continuity with maximum score of 35.

Observation Schedule cum Rating Scale for the Skill of Explanation: It consists of seven components namely: Use of explaining links, Use of introductory statements, Use of concluding statements, Covering essential points, Use of visual technique, Testing pupils understanding by asking questions, Interesting to pupils with maximum score of 49 .

Observation Schedule cum Rating Scale for the Skill of Probing Questioning: It consists of five components namely: Prompting, Seeking further information, Refocusing, Redirecting, Increasing critical awareness with maximum score of 35 .

Observation Schedule cum Rating Scale for the Skill of Stimulus Variation: It consists of six components namely: Movements, Gestures, Change in speech pattern, Focusing, Interaction styles, Pausing with maximum score of 42.

Observation Schedule cum Rating Scale for the Skill of Black Board Writing: It consists of nine components namely: Legibility, Neatness, Adequate use, Proper presentation, Writing in straight lines, Visibility, Figure at proper place, Speaking with writing, Use of coloured chalks with maximum score of 63 .

The extent of the use of the various components of different skills was rated on the seven point scale form by crossing $(x)$ the number 1 to 7 by the observer. The scale value ' 1 ' indicates that student teacher did not use the particular component at all. The scale value ' 7 ' indicates that student teacher used the particular component in an excellent manner. Total score for any session is calculated by adding rating score of all the components.

Questionnaire for Student Teachers to evaluate their Cognitive Aspect : The main purpose of this Questionnaire was to find out the knowledge of student teachers about general program 
of student teaching, teaching competence, feedback, microteaching \& teaching skills. Before the preparation of the questionnaire, the investigator consulted the various books, journals and other sources for getting latest information on the teaching in general, micro-teaching, teaching skills, components of teaching skills, teaching competence and different types of feedback. The validity of the questionnaire was checked by consulting a number of experts having long standing erudition \& experience in the field of inquiry \& the reliability of the questionnaire was determined by employing Test-Retest Method of reliability. It was found to be +0.97 . This was determined by selecting randomly $50 \mathrm{~B}$. Ed. student teachers from the session 2004-05.

\section{Procedures}

After grouping the student teachers into the Experimental Group, the cognitive based competence of student teachers was determined by administering the questionnaire prepared for this purpose by the investigator on them. Subsequently BGTC Scale was applied on each student teacher as pretest to obtain initial scores. After this all the student teachers were taught in detail about the concept of microteaching, teaching skills, and components of selected teaching skills. Subsequently each student was asked to prepare the four micro lesson plans (two for each teaching subject) of about six minutes for each of the selected skill. In this way each student teacher prepared the 20 micro lessons. Each student was trained by Student Feedback in five selected teaching skills by using microteaching cycle. Finally BGTC Scale was applied on each student teacher as posttest.

The validity of above experimental procedure had been established by conducting Pilot Study-I with ten B. Ed. student teachers of session 2003-04 and Pilot Study-II with ten B. Ed. student teachers of session 2004-05. In Pilot Study-I \& Pilot Study-II same five teaching skills as used in the present study were developed among student teachers through Student Feedback.

Data analysis involved basic descriptive statistics like mean, standard deviation to quantify the competence. Product Moment Coefficient of Correlation, Stanine Scale, t-test and Sum-ofranks Test ( $z$ ) were used to evaluate the effect of Student Feedback on teaching competence of student teachers.

\section{Results and Discussion}

The relationship between efficiency of using the five selected teaching skills and general teaching competence among the student teachers trained through Student Feedback is determined by calculating the coefficient of correlation between the overall efficiency of using five selected teaching skills and posttest BGTC Scale scores. Overall efficiency of using five selected teaching skills by the student teacher is calculated by dividing the total final score obtained by the student teacher in all the teaching skills by the maximum total score (224) of all the five teaching skills and multiplying by 100 .

Table 1 shows the relationship between efficiency of using the five selected Teaching Skills and General Teaching Competence for the student teachers trained through Student Feedback: 
Table 1. Relationship Between Efficiency of using the five selected Teaching Skills and General Teaching Competence for Student Feedback

\begin{tabular}{|c|c|c|c|c|c|c|c|c|}
\hline \multirow[t]{2}{*}{ S. No. } & \multicolumn{5}{|c|}{ Average Final Score in the Skill of } & \multirow[t]{2}{*}{ Total Score } & \multirow{2}{*}{$n$} & \multirow{2}{*}{ FS } \\
\hline & ITL & $\mathbf{E}$ & $\mathbf{P Q}$ & sv & BW & & & \\
\hline 1 & 30 & 43 & 31 & 35 & 54 & 193 & 86.16 & 112 \\
\hline 2 & 31 & 41 & 28 & 35 & 58 & 193 & 86.16 & 88 \\
\hline 3 & 29 & 39 & 27 & 37 & 55 & 187 & 83.48 & 98 \\
\hline 4 & 29 & 42 & 29 & 35 & 58 & 193 & 86.16 & 85 \\
\hline 5 & 29 & 38 & 30 & 36 & 57 & 190 & 84.82 & 86 \\
\hline 6 & 29 & 40 & 29 & 35 & 58 & 191 & 85.27 & 108 \\
\hline 7 & 28 & 41 & 31 & 35 & 56 & 191 & 85.27 & 114 \\
\hline 8 & 29 & 40 & 29 & 36 & 55 & 189 & 84.38 & 79 \\
\hline 9 & 28 & 41 & 27 & 37 & 57 & 190 & 84.82 & 84 \\
\hline 10 & 27 & 42 & 29 & 36 & 55 & 189 & 84.38 & 80 \\
\hline \multicolumn{7}{|c|}{ Mean } & 85.09 & 93.4 \\
\hline \multicolumn{7}{|c|}{$r_{n f}$} & \multicolumn{2}{|c|}{0.260} \\
\hline \multicolumn{7}{|c|}{ S/NS } & \multicolumn{2}{|c|}{ NS } \\
\hline \multicolumn{7}{|c|}{$\mathrm{S}^{*} / \mathrm{NS}^{*}$} & \multicolumn{2}{|c|}{ NS* } \\
\hline
\end{tabular}

Note $: r_{.01}$ at $(10-2=) 8 \mathrm{df}=.765 ; r_{.05}$ at $(10-2=) 8 \mathrm{df}=.632 ; \eta=$ Efficiency of Using Five Teaching Skills; FS = Posttest BGTC Scale Score; $r_{n f}=$ Coefficient of Correlation Between Efficiency of Using Five Teaching Skills and Posttest BGTC Scale Score

From Table 1 it has been found that average efficiency of using all the five selected teaching skills is 85.09 and average posttest BGTC Scale scores of the group is 93.4. Further the Coefficient of Correlation between Efficiency of Using Five Teaching Skills and Posttest BGTC Scale Score has been found to be 0.260 . This indicates low correlation between efficiency of using the five selected teaching skills and general teaching competence of the student teachers trained through Student Feedback but this value of $r_{n f}$ is less than even the tabulated value at .05 level of significance for $8 \mathrm{df}$. This reveals that there is no significant relationship between efficiency of using the five selected teaching skills and general teaching competence.

The comparison of the level of performance of student teachers trained through Student Feedback is ascertained by converting their Pretest and Posttest BGTC raw scores into Stanine scores. Table 2 provides a comparative picture of the performance of student teachers at pretest and posttest stages. 
Table 2. Performance Scores of Student Teachers at the Pretest and Posttest Stage

\begin{tabular}{|c|c|c|c|c|c|c|c|c|c|}
\hline \multicolumn{5}{|c|}{ Pretest } & \multicolumn{5}{|c|}{ Posttest } \\
\hline Stanine & Scores & Frequency & $\%$ & Category & Stanine & Scores & Frequency & $\%$ & Category \\
\hline 9 & $105+$ & 1 & 10 & ------- & 9 & $118+$ & 0 & 0 & ------ \\
\hline 8 & $99-104$ & 0 & 0 & 20 & 8 & $111-117$ & 2 & 20 & 30 \\
\hline 7 & $93-98$ & 1 & 10 & High & 7 & $105-110$ & 1 & 10 & High \\
\hline 6 & $86-92$ & 1 & 10 & ------ & 6 & $98-104$ & 1 & 10 & ------ \\
\hline 5 & $80-85$ & 2 & 20 & 60 & 5 & $91-97$ & 0 & 0 & 50 \\
\hline 4 & 74 - 79 & 3 & 30 & Average & 4 & $84-90$ & 4 & 40 & Average \\
\hline 3 & $67-73$ & 2 & 20 & ------- & 3 & $78-83$ & 2 & 20 & ------- \\
\hline 2 & $61-66$ & 0 & 0 & 20 & 2 & $71-77$ & 0 & 0 & 20 \\
\hline 1 & +60 & 0 & 0 & Low & 1 & +70 & 0 & 0 & Low \\
\hline \multicolumn{5}{|c|}{ Mean $=82.20$} & \multicolumn{5}{|c|}{ Mean $=93.40$} \\
\hline
\end{tabular}

It is clear from the above table that at pretest stage the performance of 20 percent of the student teachers is high whereas 20 percent of the student teachers fall in the category of low performance. It has also been observed that 60 percent of student teachers have shown average performance. On the other hand at the posttest stage the performance of 30 percent student teachers may be termed as superior or high whereas performance of 20 percent student teachers has been found to be low or below average. 50 percent of student teachers fall in the category of average performance. This shows that development of the teaching skills through student feedback has increased the percentage of student teachers in the high category from 20 to 30 percent i.e. 10 percent of the student teachers show an upward tendency. In other words there is shift of 10 percent of student teachers from average performance category to the high performance category. However there is no change in the percentage of student teachers showing below average performance.

For the analysis of the effect of Student Feedback on the General Teaching Competence of student teachers correlated t-test was used to find out the significance of difference between two means. Since the t-test is a parametric measure and the sample size is quite small, therefore it is not feasible to generalize the result of small sample to the population parameter by using parametric measure. Therefore, in order to eliminate sampling error and to generalize the result to the population parameter, non-parametric statistics i.e. ' $Z$ ' test was used. Thus, analysis of t-test result for general teaching competence was followed by analysis and interpretation of z-test (Sum-of-ranks Test) results.

From the Mean \& Standard Deviation (SD) of Pretest and Posttest BGTC Scores of student teachers trained by Student Feedback, Standard Error of Mean $\left(\mathrm{SE}_{\mathrm{M}}\right)$ \& Difference of Means (DM) and by using correlation coefficient between the Pretest Scores and Posttest BGTC Scores $\left(r_{\text {if }}\right)$, Standard Error of difference between means $\left(S_{\mathrm{D}}\right)$ has been calculated. Subsequently ' $\mathrm{t}$ ' ratio has been calculated and the results obtained are tabulated in Table 3: 
Table 3. Difference of Mean Between Pretest and Posttest BGTC Scores of Student Teachers

\begin{tabular}{|c|c|c|c|c|c|c|c|c|c|}
\hline Test & Mean & SD & $S E_{M}$ & DM & $r_{\text {if }}$ & $\mathrm{SE}_{\mathrm{D}}$ & $\mathbf{t}$ & S/NS & $\mathrm{S}^{*} / \mathrm{NS}^{*}$ \\
\hline Pretest & 82.20 & 12.66 & 1.51 & \multirow{2}{*}{11.20} & \multirow{2}{*}{0.52} & \multirow{2}{*}{1.53} & \multirow{2}{*}{7.31} & \multirow{2}{*}{$S$} & \multirow{2}{*}{$\mathrm{S}^{*}$} \\
\hline Posttest & 93.40 & 13.48 & 1.61 & & & & & & \\
\hline
\end{tabular}

Note : $\mathrm{t}_{.05}$ for $9 \mathrm{df}=2.26 ; \mathrm{t}_{.01}$ for $9 \mathrm{df}=3.25 ; \mathrm{S} / \mathrm{NS}=$ Significant/Non-significant at .05 level of significance; $\mathrm{S}^{*} / \mathrm{NS}^{*}=$ Significant/Non-significant at .01 level of significance;

The ' $\mathrm{t}$ ' ratio between the Pretest BGTC Scores and Posttest BGTC Scores is 7.31, which is highly significant at .01 level of significance. This shows that mean posttest score (93.40) is significantly higher than their mean pretest score (82.20). This reveals that Student Feedback results in significant improvement in the general teaching competence of the student teachers.

Table 4 shows the $Z$ value calculated by using the Sum of Ranks (SOR) between Pretest and Posttest BGTC Scores. The analysis and interpretation of results obtained is discussed below:

Table 4. Difference of Sum of Ranks of Pretest and Posttest BGTC Scores of Student Teachers

\begin{tabular}{|l|c|c|c|c|c|c|c|}
\hline Test & SOR & N & $\begin{array}{c}\text { Z- } \\
\text { Value }\end{array}$ & FTA & PNC & S/NS & S*/NS* \\
\hline Pretest & 78.00 & 10 & -2.04 & S & & & \\
\hline Posttest & 132.00 & 10 & 2.04 & 4793 & 2.07 & S & NS* \\
\hline
\end{tabular}

Note $: Z_{.05}=1.96 ; Z_{.01}=2.58 ; \mathrm{N}=$ Sample Size; FTA = Fractional Parts of Total Area (taken as 10000) under normal probability curve towards the right/left

In Table 4 the result of Student Feedback shows that 2.07 percent of the normal curve (PNC) lies to the right of $2.04 \sigma$ and 2.07 percent lies to the left. The total percent, therefore, is less than .05 . With the present evidence in hand we can state that there is significant difference between Pretest and Posttest BGTC Scores. This shows that student feedback helps in increasing the teaching competence of student teachers. The $Z$ value result confirms the result of ' $t$ ' ratio discussed earlier at .05 level of significance. Hence, the results analyzed are reliable and valid at .05 level.

Cognitive-based-competence (CBC) was measured through Standardized Questionnaire prepared for this purpose \& the performance-based-competence (PBC) of student teachers was determined through Posttest BGTC Scores. Table 5 shows the Significance of Correlation Coefficient between Cognitive-Based-Competence and Performance-Based-Competence: 
Table 5. Significance of Correlation Coefficient Between Cognitive-Based-Competence and Performance-Based-Competence

\begin{tabular}{|l|c|c|c|c|c|c|c|}
\hline Parameter & Mean & SD & $\mathbf{r}_{\mathrm{cp}}$ & $\mathbf{N}$ & $\mathbf{d f}=\mathbf{N}-\mathbf{2}$ & $\mathbf{S} / \mathbf{N S}$ & $\mathbf{S}^{*} /$ NS* $^{*}$ \\
\hline Questionnaire Score & 224.80 & 12.93 & \multirow{2}{*}{0.37} & 10 & 8 & \multirow{2}{*}{ NS } & \multirow{2}{*}{ NS* } \\
\hline Posttest BGTC Score & 93.40 & 13.48 & & & & & \\
\hline
\end{tabular}

Note $: r_{.05}$ at $8 \mathrm{df}=.632 ; r_{.01}$ at $8 \mathrm{df}=.765 ; \mathrm{df}=$ degrees of freedom

The Coefficient of Correlation between Cognitive-Based-Competence and Performance-BasedCompetence $\left(r_{c p}\right)$ had been found to be 0.37 . This shows that there is low positive relationship between CBC \& PBC for student teachers trained through Student Feedback. But this value of $r_{c p}$ is less than even the tabulated value at .05 level of significance for $8 \mathrm{df}$. This reveals that there is no significant relationship between Cognitive-Based-Competence and PerformanceBased-Competence at .05 level of significance. Therefore, Student Feedback is not effective in transforming cognitive-based-competence possessed by the student teachers into the performance-based-competence.

\section{Conclusions}

- The efficiency of using all the skills has been found to be greater than $83 \%$ in case of all the student teachers trained through Student Feedback. Thus, Student Feedback is found to be useful for developing five selected teaching skills (Skill of Introducing the Lesson, Skill of Explanation, Skill of Probing Questioning, Skill of Stimulus Variation, and Skill of Blackboard Writing) among student teachers using microteaching technique.

- The Coefficient of Correlation between Efficiency of Using Five selected Teaching Skills and Posttest BGTC Scale Score has been found to be low ( $r=0.260)$. Moreover Coefficient of Correlation is found to be non-significant at .05 level. Thus, we can conclude that Student Feedback is not much effective for developing the teaching competence through the development of five selected teaching skills.

- Student Feedback has been found to be effective in improving the level of performance of student teachers in terms of general teaching competence. $10 \%$ of the student teachers move from average to high performance category. Hence, more time should be devoted in developing teaching skills by using Student Feedback to increase the level of performance of student teachers in terms of teaching competence.

- Student Feedback results in improving the general teaching competence of student teachers. The mean difference in terms of Pretest and Posttest BGTC Scores was found to be significant. Thus, more emphasis may be given on Student Feedback for improving the general teaching competence of student teachers.

- There was non-significant positive relationship between Cognitive-Based-Competence and Performance-Based-Competence shown by student teachers trained by Student Feedback. This means that Student Feedback fails to use Cognitive-Based-Competence possessed by student teachers effectively to develop Performance-Based-Competence. 


\section{Implications}

- Teaching skills such as Skill of Introducing the Lesson, Skill of Explanation, Skill of Probing Questioning, Skill of Stimulus Variation, and Skill of Blackboard Writing can be developed among student teachers using microteaching technique. Thus, in curriculum of educational technology for B.Ed. course skill development through student feedback should be incorporated.

- For developing the teaching competence through the student feedback, the five selected teaching skills are not enough; more skills should be developed through student feedback.

- Student feedback has been found to be effective in improving the level of performance of student teachers possessing average competence. Thus, student feedback had been found to be more suitable for average students for improvement in their performance.

- Ways are to be determined to modify the student feedback delivered to the student teachers so that Cognitive-Based-Competence possessed by them can be effectively utilized to develop Performance-Based-Competence.

\section{References}

Best, J. W. \& Khan, J. V. (2002). Research in education. New Delhi: Prentice Hall of India.

Das, R. C., Passi, B. K., \& Singh, L. C. (1980). Differential effectiveness of microteaching components. New Delhi: NCERT.

Ellis, R. (1993). The Management of quality in the University of Ulster. Higher Education, 25 (3), 239-257.

Garrett, H. E. (2004). Statistics in psychology and education. New Delhi: Paragon International.

Gibbs, G. (1995). How can promoting excellent teachers promote excellent teaching? Innovations in Education and Training International, 32(1), 74-84.

Hendry, G. D., Lyon, P. M., \& Henderson-Smart, C. (2007). Teachers' approaches to teaching and responses to student evaluation in a problem-based medical program. Assessment \& Evaluation in Higher Education, 32(2), 143-157.

Johnson, K. E. (2000). Constructive evaluations. Science Teacher, 67(2), 38-41.

Joshi, V. (2002). Feedback from students: An exercise worth undertaking. University News, 40(1), 10-12.

Passi, B. K. \& Lalitha, M. S. (1976). Microteaching in Indian context. Research Bulletin.

Passi, B. K. (1976). Becoming better teacher: Microteaching approach. Ahmedabad: Sahitya Mundranalya.

Purohit, Z. N. (1987). An experimental study of the effect of micro teaching skills and interaction analysis feedback on classroom performance and general teaching competence of pre-service language teachers. In M.B. Buch (Ed.), Fourth survey of research in education: 1983-1988 (p.976). New Delhi: NCERT. 
Rauch, M. \& Fillenworth, C. (1995). Motivating students to use newly learned study strategies. Journal of Adolescent \& Adult Literacy, 38(7), 567-568.

Richardson, J. T. E. (2005). Instruments for obtaining student feedback: A review of the literature. Assessment and Evaluation in Higher Education, 30(4), 387-415.

Sharma, R. A. (2000). Essential of scientific behavioral research, Meerut: R. Lal Book Depot.

Walker, C. J. (1991). Classroom research in psychology: Assessment techniques to enhance teaching and learning. New Directions for Teaching and Learning, 46, 67-78.

Correspondence: Dr. Vibha Chawla, Senior Lecturer, Rayat-Bahra College of Education, Hoshiarpur, Punjab, India 